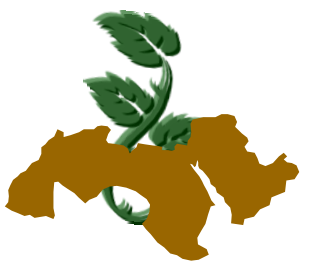

Arab Univ.

J. Agric. Sci., Ain Shams Univ., Cairo, 23(1), 121 - 135, 2015

\title{
COMPARATIVE EFFECTS OF THERMAL TREATMENTS AND $\gamma$-IRRADIATION ON THE VOLATILE, NON-VOLATILE AND ANTIRADICAL ACTIVITY OF EGYPTIAN ANISE ESSENTIAL OIL
}

\author{
Mostafa M. Ismail'; Mohamed Abass' ${ }^{1}$; Magda A. Abd El Mageed ${ }^{2}$; \\ Fouad. Osman ${ }^{2}$; Karima. A. Mahmoud ${ }^{3}$, Engy. M. Mohamed ${ }^{2}$ \\ and Gamil.E.Ibrahim ${ }^{2}$
}

1- Department of Chemistry, Faculty of Education, Ain Shams University, Roxy, Cairo 11757, Egypt

2- Chemistry of Flavour \& Aroma Dept National Research Center. NRC, Dokki, Giza, Egypt

3- Food Irradiation Dept., Atomic Energy Authority, National Centre for Radiation Research and Technol, Egypt

Corresponding E-Mail: magdaelmaged@hotmail.com

Keywords: Anise oil, thermal processing, $\gamma$ irradiation, antioxidant, volatile and nonvolatile.

\section{ABSTRACT}

The effect of various thermal treatments (electric oven, microwave) and $\gamma$-irradiation at three doses (6, 8 and $10 \mathrm{KGy}$ ) on the composition of volatile and non-volatile of anise essential oil and also their antioxidant properties were considered. The hydrodistilled oil (HD) of control and treated samples were subjected to gas chromatographymass spectrometry (GC/MS) analysis.

The volatile profile of raw HD oil of anise consisted mainly of transe-anethole $(79.68 \%)$ followed by hexahydrofarnesyl acetone $(6.95 \%)$, paraanisaldehyde (5.49\%); $\gamma$-himachalene $(2.53 \%)$ and estragole $(0.76 \%)$. Although the effect of roasting didn't cause significant changes in the total yield of major compounds of HD anise oil which are phenylpropanoid derivative (transe anethole , paraanisaldehyde, cis-anethole and estragole (=methylchavicol), it is found that gamma irradiation revealed the same behavior at the $10 \mathrm{KGy}$ irradiated sample but decrease the total yield of these compounds in 6.8 KGy irradiated sample compared to control one. also the thermal and $\gamma$ irradiation caused drastic increase in the total yield of sesquiterpenes whereas decreased oxygenated compounds in all samples under investigation compared to control one.

Such changes affected the antioxidant activity of the treated samples 1.1-diphenyl-2picrylhydrazyl (DPPH) free radical scavenging as well as $\beta$-carotene bleaching test against butylated hydroxy toluene (BHT).

The strongest effect of reduction of DPPH radical as well as the highest inhibiting effect of the oxidation of linoleic acid and the subsequent bleaching of $\beta$-carotene was by $8 \mathrm{KGy}$ irradiated sample which comprised (84.57\% \pm 1.43$)$; $(85.21 \%$ $\pm 0.12)$ respectively, in comparison to $\mathrm{BHT}(98 \% \pm$ 0.0 ) at the same concentration $30 \mu \mathrm{g} / \mathrm{mL}$ besides all samples under investigation revealed high antioxidant activities due to their high content of phenylpropanoid and oxygenated compounds.

These confirmed by total phenolic content.

High performance liquid chromatography (HPLC) method was used for the analysis of phenolic compounds in the selected sample. Polyphenolic compounds were analysed on $\mathrm{C}_{18}$ Reversed Phase (RP) HPLC. A total of 9 phenolic compounds were identified, the obtained results showed that the predominant compound was $P$ qumaric acid (43.36\%) followed by ferulic acid (21.06\%).

\section{INTRODUCTION}


Recently, spices have received attention also in their useful physiological functions and antimicrobial activity. There are a lot of reports about antimicrobial activity of spice extracts and its essential oils. However, the available information's are for a small group of microorganisms and they are tested at high concentrations which are no practical use. More research is required on antimicrobial effects to food-related bacteria such as food spoilage bacteria and food borne bacterial pathogens (Roby et al 2013).

In food processing, lipid oxidation not only causes a loss in nutritional and gustative quality of foods but also generates oxidized products such as free radicals which lead to various undesirable chemical reactions. To avoid or delay this autoxidation process, conventional artificial antioxidants such as butylated hydroxyanisole (BHA) and butylated hydroxy toluene (BHT), propyl gallate $(P G)$ and tertiarybutylhydroquinone (TBHQ) have been used for more than five decades (Li and Yi., 2003). However, these synthetic antioxidants have been suspected to or promote negative health effects. For this reason, there is a growing interest in studies of natural additives as potential antioxidants. Many sources of antioxidants of plant origin have been studied in recent years. Among these, the antioxidant properties of many aromatic and medicinal plants have shown to be effective in retarding the process of lipid peroxidation in oils and fatty foods and have gained the interest of many research groups (Kulisic et al 2004). Therefore, the demands for these plants are increasing in industrialized and non-industrialized countries which lead to increasing their prices.

Anise (Pimpinella anisum L.) is one of the most widely used plants in the world; anise seed is used as a spice (Leela and Vipin, 2008). and Anise seed essential oil has a number of applications as an aromatic agent in the food and liquor industry (Leela \& Vipin, 2008 and Tonutti \& Liddle, 2010). Commercial production of anise seed and anise essential oil is concentrated in countries in south Asia, Europe, North Africa as Egypt, and also in Russia. $P$. anisum is primarily cultivated for its fruits, commercially called "seeds" that are currently used for flavouring. Anise fruits are widely used in the preparation of traditional bread and baking goods, in liquor, and for aromatization of traditional Bulgarian liquor annasonliika, whereas anise essential oil is used as an aromatic agent in the pharmaceutical, perfumery, cosmetics, and candy production industries (Tonutti and Liddle, 2010). Many folk medicinal systems from Asia to the Mediterranean are still using anise seed as a medicinal plant (Leela and Vipin, 2008). For example, Bulgarian traditional medicine has been using anise seed or anise seed extract as an anesthetic, antispasmodic, carminative, for treating coughs, bronchitis, asthma, other inflammatory diseases, kidney stones, and for increasing lactation in nursing mothers (Stojanov, 1973).

With the increased use of herbs and spices for food preservation and their inclusion in nutritional recommendations (Tapsell et al 2006), the importance for adequate preservation methods for herbs has become more important. Treatment with ionizing radiation is an accredited preservation method. Although the safety of irradiated food is well documented (World Health organization "WHO", 1999), little is known about the effects of irradiation on the antioxidant activity of phytochemicals.

The Joint FAO/IAEA/WHO Expert Committee confirmed that irradiation up to $10 \mathrm{kGy}$ does not produce toxicological hazards and nutritional or microbiological problems in foods (WHO, 1981). Dried foods, such as fennel powder, are less sensitive to irradiation than hydrated ones, and their irradiation has been authorized at a maximum dose of $10 \mathrm{kGy}$ and $30 \mathrm{kGy}$ in Korea and in the United States, respectively (Olson, 1998). An irradiation dose of 5 to $10 \mathrm{kGy}$ is sufficient to reduce the population of microbes without changing essential quality attributes, and the spice flavuor remained intact up to 7.5 kGy (Farkas, 1985). However, unsaturated hydrocarbons were created in gamma-irradiated ground chili and paprika at 5 and 10 kGy and increased with the dose of irradiation (Bendini et al 1998). Furthermore, spices are usually irradiated in prepackaged form to prevent postcontamination. In this case, possible abnormal compounds from packaging materials may be created by irradiation and may migrate into the foods. Consequently, this migration may be potentially harmful and impact food flavour (Krzymien et al 2001). In addition, microwave energy has been used in food processing applications mainly for its heating properties. Therefore, it seems natural to adapt microwave radiation to pasteurize or even sterilize foods at lower temperatures or for shorter times than conventional methods require (Fung and Cunningham, 1980).

Research during the past 30 years on spices and herbs proved that treatment with ionizing radiation is an effective process for destroying insects and 

and Antiradical activity of Egyptian anise essential oil

micro-organisms parkas, lonizing radiation requires no additives and is a safe physical process with a controllable technology. A major advantage for ionizing radiation is that it is cold treatment and hence this treatment does not cause any loss of the volatile components of the spices. The use of microwave energy for heating has been around for 40 years (Basaran and Akhan, 2010). Its potential use in the food processing industry for pasteurizing, sterilizing, defrosting, blanching, dehydration and cooking has opened a new dimension in food preparation at home and in food service operation (Thostenson and Chou, 1999 and AbdElmageed et al 2011, 2012, 2014)).

Commercial and legal requirements regarding the safety, quality and storage of food products have still focused attention on the development and improvement of decontamination methods. Microwave processing and cooking of foods is a recent development, which is gaining momentum in household as well as large scale food applications (Basaran and Akhan, 2010). Microwave energy has been used in food applications mainly for its heating properties. It seems natural, therefore, to adapt microwave radiation to pasteurize or even sterilize foods at low temperatures in shorter times than required by conventional methods (Akgul et al 2008 and Abd-Elmageed et al 2011, 2012). Due to the absorption of electromagnetic energy, temperature of material of high dielectric capacity increases after microwave pasteurization. Therefore, microwave pasteurization offers similar benefits to conventional methods, but with an improved product quality and reduced time of exposure to energy (Hashem and Alamri, 2010). Processing of spices using microwaves is a newer dimension. This alternative methodology is preferred, due to the convenience and ease of handling (Abd-Elmageed, 2007).

Cooking or roasting alters the nature of many food constituents such as starches and proteins by changing their physical, chemical and nutritional characteristics (Belitz and Grosch, 1987). Heat processing also changes the bioavailability of proteins, carbohydrates, lipids and vitamins. Little information is available on the extent of destruction of bioactive principles of spices during food processing. Since the healthy, beneficial physiological effects of spices are attributable to their active principles (Srinivasan, 2005), there is a need to evaluate the availability of the spice active principles in their original form when spices are heat processed as in domestic cooking. Significant losses in the concentration of active principles would raise a question as to whether the spices would retain beneficial health effects after conventional heat processing, as in domestic food preparation.

Generally, some spices are processed, for their microbial stability and removal of extraneous matter. Roasting is one of the important phases in the cooking process to release characteristic flavour volatiles (Susheela, 2000) and undesirable constituents. Hence, roasting of spices affects flavour quality.

The present work deal with the evaluation of some thermal treatments (conventionally roasting by electric oven and microwave heating) which were suggested to decontaminate the spices and to compare the results with a $\gamma$-irradiation doses (6,8 and $10 \mathrm{kGy}$ ) which (so-called cold sterilization) were recommended for this purpose as standard work. The evaluations included phenolic content, antiradical activities, volatile and non-volatile compounds to choose the best results in this comparative study for improving the quality of Egyptian anise.

\section{MATERIALS AND METHODS}

\section{Plant materials}

Seeds of Anise (Pimpinella anisum L.) were purchased from local market at Giza during 2014.

\section{Chemicals}

1,1-Diphenyl-2-picrylhydrazyl (DPPH), butylated hydroxy toluene (BHT), $\beta$-carotene, gallic acid and Folin-Ciocalteu reagents and standard hydrocarbons $\left(\mathrm{C}_{8}-\mathrm{C}_{22}\right)$ were obtained from Sigma Chemical Co. Methanol and formic acid (HPL grade) were purchased from Aldrich Co. All other solvents and chemicals were of analytical grade.

\section{Thermal processing and irradiation of anise samples}

Fresh three dry anise seed samples (100 g each) were roasted in a separately conventional electric oven at $120^{\circ} \mathrm{C}$ and for 20 minutes. Similarly, three samples (100 $\mathrm{g}$ each) were subjected to microwave heating (Daewoo DE Microwave, Mod: KoG-181G, 200-240V 50Hz. Microwave input power was $1400 \mathrm{~W}$, Korea) separately and roasted after 3 minutes.

The Anise-seed samples were packaged in a sanitized brown glass capped bottles (1L) and irra- 
diated in Radiation Research Centre, Cairo, Egypt by $\gamma$-cell, cobalt- $60 \gamma$-irradiator at dose rate 1.29744 $\mathrm{KGy} /$ hours. The applied doses in this study were $0,6,8$ and $10 \mathrm{kGy}$. The actual doses were within $75.4 \%$ of the target dose (Choi et al 2010). The irradiation room temperature was $18^{\circ} \mathrm{C}$. The nonirradiated control was placed outside the irradiation chamber to have the same environmental temperature effect with the irradiating sample. The irradiated anise samples were transferred and kept in dry place the raw and treated samples were separately ground in a spice mix grinder.

\section{Isolation of essential oil}

Portions $(100 \mathrm{~g})$ of each raw, heated and irradiated samples prepared plant material were hydrodistilled for 3 hours in a Clevenger type apparatus according to the method recommended in the European pharmacopeia to isolate the essential oil. The obtained essential oils were dried over anhydrous sodium sulphate. The collected essential oils of raw and treated samples were immediately analyzed using GC and GC-MS.

\section{Gas chromatographic (GC) analysis}

GC analysis was performed by using HewlettPackard model 5890, USA equipped with a flame ionization detector (FID). A fused silica capillary column DB-5 (60m x0.32 mm. id,) was used. The oven temperature was maintained initially at $50^{\circ} \mathrm{C}$ for $5 \mathrm{~min}$., then programmed from 50 to $250^{\circ} \mathrm{C}$ at a rate of $4^{\circ} \mathrm{C} / \mathrm{min}$. Helium was used as the carrier gas, at flow rate of $1.1 \mathrm{ml} / \mathrm{min}$. The injector and detector temperatures were 220 and $250^{\circ} \mathrm{C}$, respectively. The retention indices (Kovats index) of the separated volatile components were calculated using hydrocarbons $\left(\mathrm{C}_{6}-\mathrm{C}_{22}\right)$, Aldrich $\left.\mathrm{Co}_{0}\right)$ as references.

\section{Gas chromatographic-Mass spectrometric analysis}

The analysis was carried out by using a coupled gas chromatography Hewlett-Packard model (5890)/mass spectrometery Hewlett-Packard-MS (5970). The ionization voltage was $70 \mathrm{eV}$, mass range $\mathrm{m} / \mathrm{z}$ 39-400 amu. The GC condition was carried out as mentioned above. The isolated peaks were identified by matching with data from the library of mass spectra (National Institute of Standard and Technology) and compared with those of authentic compounds and published data (Adams et al 2007). The quantitative determina- tion was carried out based on peak area integration.

\section{Antioxidant activity assay}

Anise essential oils and their extracts used for the determination of the antioxidant activity assays, and total phenolic content (TPC) were prepared as follow: $1 \mathrm{~g}$ of respective solid anise was mixed $100 \mathrm{ml} 80 \%(\mathrm{v} / \mathrm{v})$ water/methanol or ethanol solution and the suspension was shaken for 1 hour using a laboratory shaker at $1000 \mathrm{rpm}$. The solid phase was separated using filtration and this step was carried out in triplicate and the final extracts were stored in closed viales in darkness at $4^{\circ} \mathrm{C}$.

\section{DPPH scavenging assay}

Each extract $(10,20,30 \mu \mathrm{g} / \mathrm{ml})$ in methanol was mixed with $3 \mathrm{ml}$ of methanolic solution containing DPPH radicals. The mixture was shaken vigorously and left to stand for $30 \mathrm{~min}$ in the dark, and the absorbance was then measured at $517 \mathrm{~nm}$ using spectrophotometer (Shimadzu, UV-160-IPC, Japan) against a blank (Najja et al 2011).

\section{$\beta$-Carotene scavenging activity assay}

The antioxidant activity of ethanolic and methanolic extracts of raw and all treated samples of anise was performed using $\beta$-Carotene bleaching assay (BCBA) according to (lqbal et al 2007). $\beta$ Carotene $(0.1 \mathrm{mg})$ in $0.2 \mathrm{ml}$ of chloroform, $10 \mathrm{mg}$ of linoleic acid and $100 \mathrm{mg}$ of tween 40 were mixed. The solvent was removed at $40^{\circ} \mathrm{C}$ under vacuum and the resulting mixture, $20 \mathrm{ml}$ of oxygenated water was added. four milliliter aliquots mixtures were pipetted into different test tubes containing $10 \mu \mathrm{g}$ of each extract $(10,20,30 \mu \mathrm{g} / \mathrm{ml})$ in ethanol. All determinations were carried out in triplicate.

\section{Determination of total phenolic content (TPC)}

Total phenolic content (TPC) of raw and anise treated samples were spectrophotometrically determined by Folin Ciocalteu reagent assay according to Singleton (1998), using gallic acid in methanol (50-2500mg/L) served as an external standard. Samples, standards, and blanks were mad in triplicate. The sample absorbance (indicative for polyphenols) was determined photommetrically at $760 \mathrm{~nm}$. Result are expressed as milligrams of gallic acid equivalent per $100 \mathrm{~g}$ DW (mg GAE/ $100 \mathrm{gDW}$ ).

\section{HPLC analysis}




\section{Extraction procedure}

According to the results obtained in the previous experiments, the extraction parameters finally selected were $25^{\circ} \mathrm{C}$ of temperature, and the use of a mixture of water: methanol $(80: 20)$. Two hundred and fifty milligram of powdered plant material were sonicated with $25 \mathrm{ml}$ of the solvent mixture in an ultrasonic bath for 20min. After centrifugation at $7600 \times \mathrm{g}$ for $10 \mathrm{~min}$, the supernatant was adjusted to $25 \mathrm{ml}$ in a measuring flask. Samples were quantified immediately after extraction in order to avoid possible chemical alterations. Blanks and standards containing known concentrations were placed between the samples to monitor the quantification.

\section{HPLC analysis instrumentation}

Analyses were carried out in a Aglient 100 series 1050 chromatograph equipped with an automatic injector, vacuum degasser and a DAD system. A Discovery ${ }^{\circledR} \mathrm{HS} \mathrm{C}_{18}(250 \mathrm{~mm} \times 4.8 \mathrm{~mm}, 5 \mathrm{um})$ column (Supelco, Bellefonte, PA, USA) was used for all the separations. The mobile phase was a gradient prepared from $0.1 \%$ formic acid in water (A) and $0.1 \%$ formic acid in acetonitrile (B). The composition ranged from $10 \% \mathrm{~B}$ to $26 \% \mathrm{~B}$ in $40 \mathrm{~min}$. The flow rate was $0.2 \mathrm{ml} \mathrm{min}^{-1}$, and the injection volume 50 ul. UV detection was performed at $280 \mathrm{~nm}$.

\section{Statistical analyses}

Statistical analyses were performed using SPSS for Windows version 16.0. Student's t-test analyzed differences between samples and controls. One-way ANOVA tested differences within the irradiated and corresponding non-irradiated samples. Correlations were calculated using Pearson's correlation coefficient. All data are presented as mean \pm SD. The significance level $\alpha$ was set at $p<0.05$.

\section{RESULTS AND DISCUSSION}

Volatile components in hydrodistillation oil (HD) of raw, conventionally roasted, microwave heated and $\gamma$-irradiated at 6,8 and $10 \mathrm{KGy}$ anise seeds.

Seeds of anise (Pimpinella anisum L.) subjected to conventionally roasting and microwave heat- ing as well as exposed to gamma irradiation at 6,8 and $10 \mathrm{KGy}$ in a ${ }^{60} \mathrm{CO}$ package irradiator. These samples were analyzed and a comparison was done between these treatments and raw sample. In the case of raw sample, the volatile oil recovered after $3 \mathrm{~h}$ of hydrodistillation (HD) was $1.06 \%$. Whereas HD volatile oil increased in all treated sample since in electric oven roasted sample yield $1.15 \%$; microwave heated sample yield $1.5 \%$; irradiated samples yield $1.08 \% ; 1.16 \%$ and $1.31 \%$ $(w / w)$ in 6,8 and 10 KGy, respectively. Eighteen volatile compounds were identified in HD oil of anise of all samples under investigation. All these compounds are listed with their area percentages in Table (1). Identification of the volatile compounds was identified by KI values and MS spectra (Adams, 2007).

The typical gas chromatograms of the volatiles in HD oil of raw, rosated samples by electric oven and microwave heated; irradiated samples at different doses 6,8 and $10 \mathrm{KGy}$ from anise seeds are showen in (Figs. 1 and 2). The total area percentages of the main chemical classes of all previous samples are shown in (Fig. 3).

The volatile profile of raw HD oil of anise consisted mainly of trans-anethole $(79.68 \%)$ followed by hexahydrofarnesyl acetone $(6.95 \%)$, paraanisaldehyde (5.49\%); $\gamma$-himachalene $(2.53 \%)$ and estragle $(0.76 \%)$ Table (1). These results are in accordance with many authors (Ullah and Honermeier 2013; Yan et al 2011; Tepe et al 2006 and Arslan et al 2004). It is well known that the major components of HD oil of anise are phenylpropanoid derivatives; trans-anethole, paraanisaldehyde, cis-anethole and estragole (=methylchavicol). Although the effect of roasted by electric oven and microwave heating did not cause significant change in the total area percentage of these compounds since it comprised $85.64 \%$ and $84.80 \%$ respectively, compared to control sample which comprised $85.93 \%$ (Fig. 3). It is found that $\gamma$-irradiation caused decrease in $\mathrm{HD}$ oil of irradiated samples at 6 and 8 KGy which comprised $80.69 \%$ and $80.64 \%$ whereas increased to reach $85.32 \%$ at $10 \mathrm{KGy}$ compared to control sample (85.93\%) Fig. (3).

These compounds are the main constituents responsible for the antioxidant activities of oils which contain them (Avlessi et al 2004). In our study, the total percentage of these compounds ranged between $80.64 \%$ to $85.64 \%$ in the HD anise seed oil of $8 \mathrm{KGY}$ irradiated sample and electric oven roasted sample, respectively. Then it is extremely expecting that all samples under investi- 
gation must have high antioxidant capacity due to their high percentage of these compounds especially trans-anethol, para-anisaldehyde.

Tepe et al (2006) found that benzene derivatives are represent in high amount $97.6 \%$ in HD of anise oil.

Esragoale, the flavouring agent is considered to have negative effects on animal and human health and was deleted from the list of flavourings in food stuffs (Burt, 2004). The European Pharmacopeia (2005) limit of estragole in essential oil of anise $0.5-6.0 \%$ was not exceeded in investigated samples. In our study estragole was found ranged between $0.66 \%$ to $1.49 \%$ in HD oil of 6 and $8 \mathrm{KGy}$ irradiated samples, respectively. (Table 1).

Conventionally, roasted caused increase in the total yield of sesquiterpenes $(4.47 \%)$ whereas microwave heating and $\gamma$-irradiation at 6,8 and 10 KGy caused drastic increase in the same compounds which comprised $7.43 \%, 7.18 \%, 10 \%$ and $8.18 \%$ respectively compared to control one $3.93 \%$ (Fig. 3). This is due to the increase of $\beta$ caryophellene, $\gamma$-elemene; $\gamma$-curcumene; $\alpha$ muurolene; $\gamma$-cadinene and $\alpha$-zingberene in the microwave and three irradiated samples whereas these compounds are not detected in control one Table (1). Besides increase in the percentage of aromadendrene and remarkable increase in the major sesquiterpene $\gamma$-himachalene which comprised in microwave and $\gamma$-irradiated samples $3.90 \%, 4.40 \%, 5.83 \%$ and $4.84 \%$, respectively in comparison to its concentration $(2.53 \%)$ in control one Table (1). These results are in accordance with Zheljazkov (2013), who reported that, the yield of $\gamma$-himachalene increase steadily with increasing distillation time to reach maximum at 480 minute. Also, these results are in agreement with Abd-Elmageed et al 2014, 2012, 2011, Leganani et al 2001; Chacko et al 1996 and Emam et al 1995).

In contrary what takes place in our previous study (Abd-Elmageed et al 2011) the effect of roasted (electric oven or microwave heating) and $\gamma$ irradiation on the yield of oxygenated terpenoids of HD anise seeds oil, show a remarkable decrease in all samples under investigation in comparison with their percentage in control (unprocessed) sample (Fig. 3). Except irradiated sample at 6 KGy it appear a remarkable increase in the total yield of heavy oxygenated compounds which comprise $12.06 \%$ compared to their concentrations (10.12\%) in control one (Fig. 3). This is due to a remarkable increase in the percentage of terpenylketone (hexahydrofarnesylacetone) in this sample (9.04\%)
Table (1). Oxygenated terpenes exhibited a higher antioxidant power in comparison to other the identified classes (Radonic and Milos, 2003).

Higher percentages of phenolic content and oxygenated compounds was strongely contribute to the fragrance and antioxidant activity (Reverchon and Senator, 1992).

\section{Antioxidant activity of the HD anise seeds es- sential oils}

Radical scavenging ability tests aim to simulate basic mechanisms involved in lipid oxidation by measuring either the reduction of stable radicals or radicals generated by physical mechanisms or chemical reactions.

The profile of scavenging activity on DPPH radical as well as the evaluated antioxidant activity using B-carotene/linoleate assays are shown in Fig. $(4,5)$, for raw, conventionally roasted, microwave and $\gamma$-irradiated 6,8 and $10 \mathrm{KGy}$ anise seeds essential oil. The radical scavenging activity of essential oil on DPPH increased with increasing concentration of the oil. The strongest effect for reduction of DPPH radical was by $8 \mathrm{KGy}$ irradiated sample $(84.57 \% \pm 0.08)$ followed by $6 \mathrm{KGy}$ irradiated sample $(83.33 \% \pm 0.07)$, respectively compared o BHT $(98 \% \pm 0.0)$ at the same concentration Fig. (4), it can be seen that percent DPPH radical scavenging activities of the extracts were dose dependent. As shown in Fig. (5), the highest inhibiting effect for oxidation of linoleic acid and the subsequent bleaching of B-carotene also was by 8 KGy irradiated sample followed by 6 KGy irradiated sample $(85.21 \%$ and $82.16 \%)$ respectively compared to BHT (98\%) scavenging radical. These results are confirmed in (Fig. 6) which showed the total phenolic content of irradiated samples besides all samples under investigation show high antioxidant activity due to higher percentage of phenolic propaniods and oxygenated compounds these results are in accordance with (Reverchon and Senator, 1992; Tepe et al 2006 and Mansour et al 2010). Polyphenols are thermally labile molecules; they get easily degraded upon heat treatment (Podsedek et al 2008 and Roy et al 2007). In case of roasted samples, occurrence of Maillard reactions at very high temperature (160 $\left.{ }^{\circ} \mathrm{C}\right)$ might also contribute to the reduction of polyphenol levels. Manzocco et al (2001) reported that polyphenolic compounds take part in Maillard reaction which results in an increase in the Maillard reaction products and a decrease in the polyphenol level. 


\section{and Antiradical activity of Egyptian anise essential oil}

Table 1. Volatile components isolated in the hydrodistillation anise seed oil of raw, electric oven, microwave and $\gamma$-irradiation at 6,8, and $10 \mathrm{KGy}$. ( ${ }^{*}$ Values expressed as relative area parentages to total identified compounds)

\begin{tabular}{|c|c|c|c|c|c|c|c|c|c|c|}
\hline \multirow[b]{2}{*}{$\begin{array}{l}\text { Peak } \\
\text { No. }\end{array}$} & \multirow[b]{2}{*}{$\mathbf{K I}^{\mathbf{a}}$} & \multirow[b]{2}{*}{ Compound } & \multirow[b]{2}{*}{$\begin{array}{c}\text { Control } \\
\text { (Raw) }\end{array}$} & \multicolumn{2}{|c|}{ Roasted } & \multicolumn{3}{|c|}{$\gamma$-Irradiation (KGY) } & \multirow[b]{2}{*}{ Type } & \multirow[b]{2}{*}{$\begin{array}{l}\text { Identification } \\
\text { method }^{b}\end{array}$} \\
\hline & & & & $\begin{array}{c}\text { Electric } \\
\text { oven }\end{array}$ & Microwave & 6 & 8 & 10 & & \\
\hline 1 & 1202 & Estragole & $0.76^{*}$ & 0.83 & 1.17 & 0.66 & 1.49 & 1.41 & Ph.Pro.Der. & MS\&KI \\
\hline 2 & 1264 & (Z) Anethole & - & 0.25 & 0.37 & 0.18 & 0.44 & 0.36 & Ph.Pro.Der. & MS\&KI \\
\hline 3 & 1271 & Para-Anisldehyde & 5.49 & 6.04 & 5.60 & 4.79 & 6.32 & 4.72 & Ph.Pro.Der. & MS\&KI \\
\hline 4 & 1299 & (E) Anethole & 79.68 & 78.52 & 77.66 & 75.06 & 72.39 & 78.83 & Ph.Pro.Der. & MS\&KI \\
\hline 5 & 1389 & $\beta$-Elemene & 1.10 & 0.68 & 0.86 & 0.41 & 0.51 & 0.29 & $\mathrm{~s}$ & MS\&KI \\
\hline 6 & 1457 & $\beta$-Caryophyllene & - & 0.34 & 0.31 & 0.27 & 0.30 & 0.27 & $\mathrm{~s}$ & MS\&KI \\
\hline 7 & 1463 & $\gamma$-Elemene & - & n.d & 0.36 & 0.24 & 0.36 & 0.39 & $S$ & MS\&KI \\
\hline 8 & 1480 & $\gamma$-Curcumene & - & 0.24 & 0.28 & 0.18 & 0.33 & 0.29 & $S$ & MS\&KI \\
\hline 9 & 1486 & Aromadedrene & 0.30 & 0.16 & 0.42 & 0.41 & 0.63 & 0.51 & $S$ & MS\&KI \\
\hline 10 & 1491 & $\gamma$-Himachalene & 2.53 & 2.29 & 3.90 & 4.40 & 5.83 & 4.84 & $S$ & MS\&KI \\
\hline 11 & 1498 & a-Muurolene & - & n.d & 0.34 & 0.37 & 0.63 & 0.43 & $S$ & MS\&KI \\
\hline 12 & 1512 & $\gamma$-Cadiene & - & 0.33 & 0.53 & 0.56 & 0.86 & 0.70 & $\mathrm{~s}$ & MS\&KI \\
\hline 13 & 1532 & $\alpha$-Zingiberene & - & 0.43 & 0.43 & 0.41 & 0.55 & 0.36 & $S$ & MS\&KI \\
\hline 14 & 1594 & $\beta$-Caryophyllene oxide & - & 0.36 & 0.16 & 0.11 & 0.43 & 0.15 & $\mathrm{HOC}$ & MS\&KI \\
\hline 15 & 1687 & $\alpha$-Cadinol & - & 0.34 & 0.40 & 0.07 & 0.57 & 0.30 & $\mathrm{HOC}$ & MS\&KI \\
\hline 16 & 1845 & Hexahydrofarnesylacetone & 6.95 & 7.42 & 5.73 & 9.04 & 6.09 & 4.88 & $\mathrm{HOC}$ & MS\&KI \\
\hline 17 & 1902 & (E) Phytol & 1.44 & 1.20 & 1.05 & 2.32 & 1.34 & 0.95 & $\mathrm{HOC}$ & MS\&KI \\
\hline 18 & 1963 & (E) Phytol acetate & 1.73 & 0.58 & 0.42 & 0.52 & 0.44 & 0.32 & $\mathrm{HOC}$ & MS\&KI \\
\hline
\end{tabular}

${ }^{a}: \mathrm{KI}$ : Linear Kovat indices:Compounds listed according to their elution on DB- 5 column; ${ }^{\text {b: }}$ compounds identified by GCMs (MS) and / or Kovat index on DB5 (KI) and / or by comparison of MS and KI of standard compounds run under similar GCMS conditions. -: not detected.

Ph.Pro.Der.: Phenylprpanoids derivatives, S:Sesquterpene hydrocarbons, HOC: Heavy oxygenated compounds; 

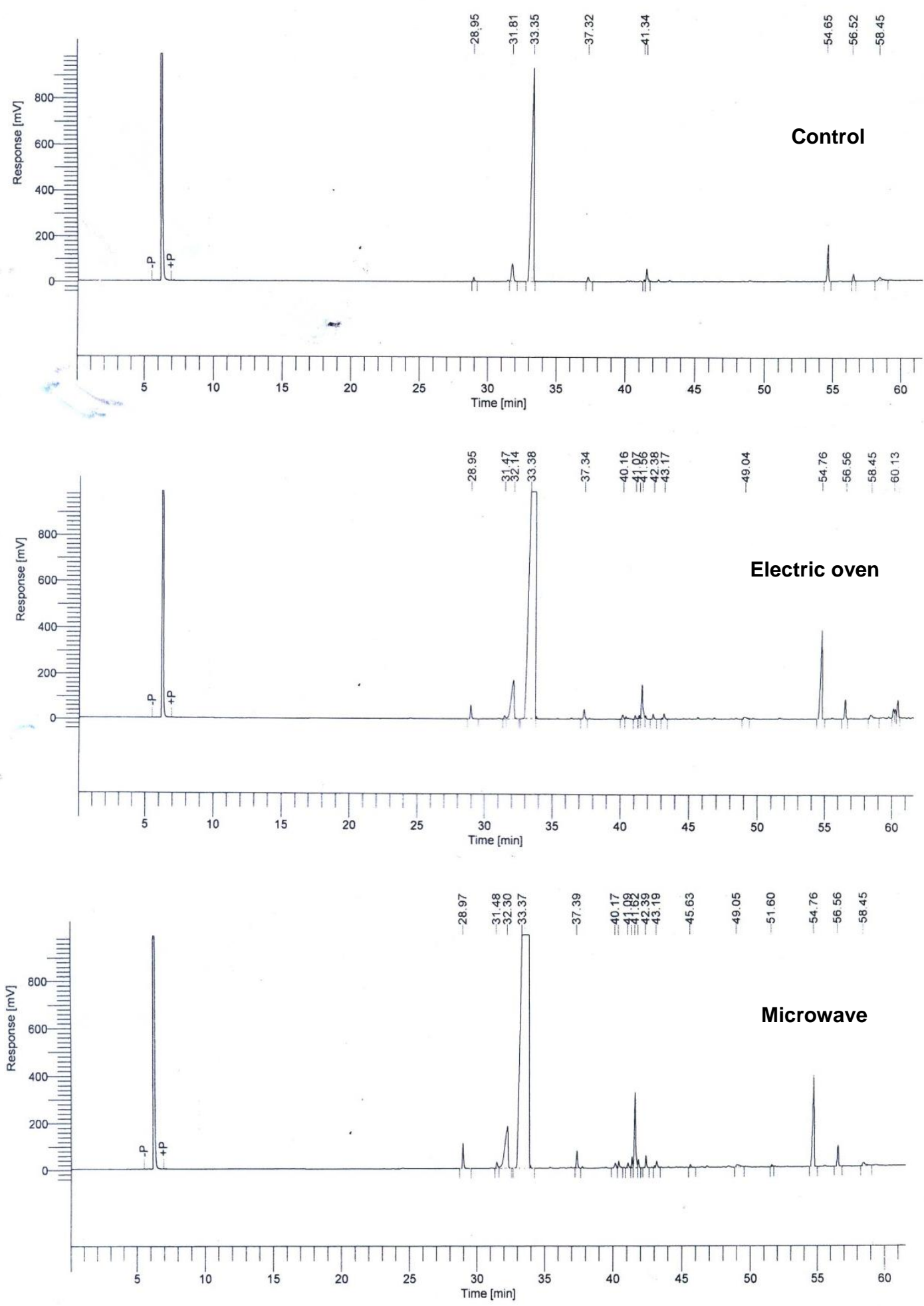

Fig. 1. Gas Chromatograms of volatiles in HD oil of raw (control), thermally roasted (electric oven) and microwave heated anise seeds 

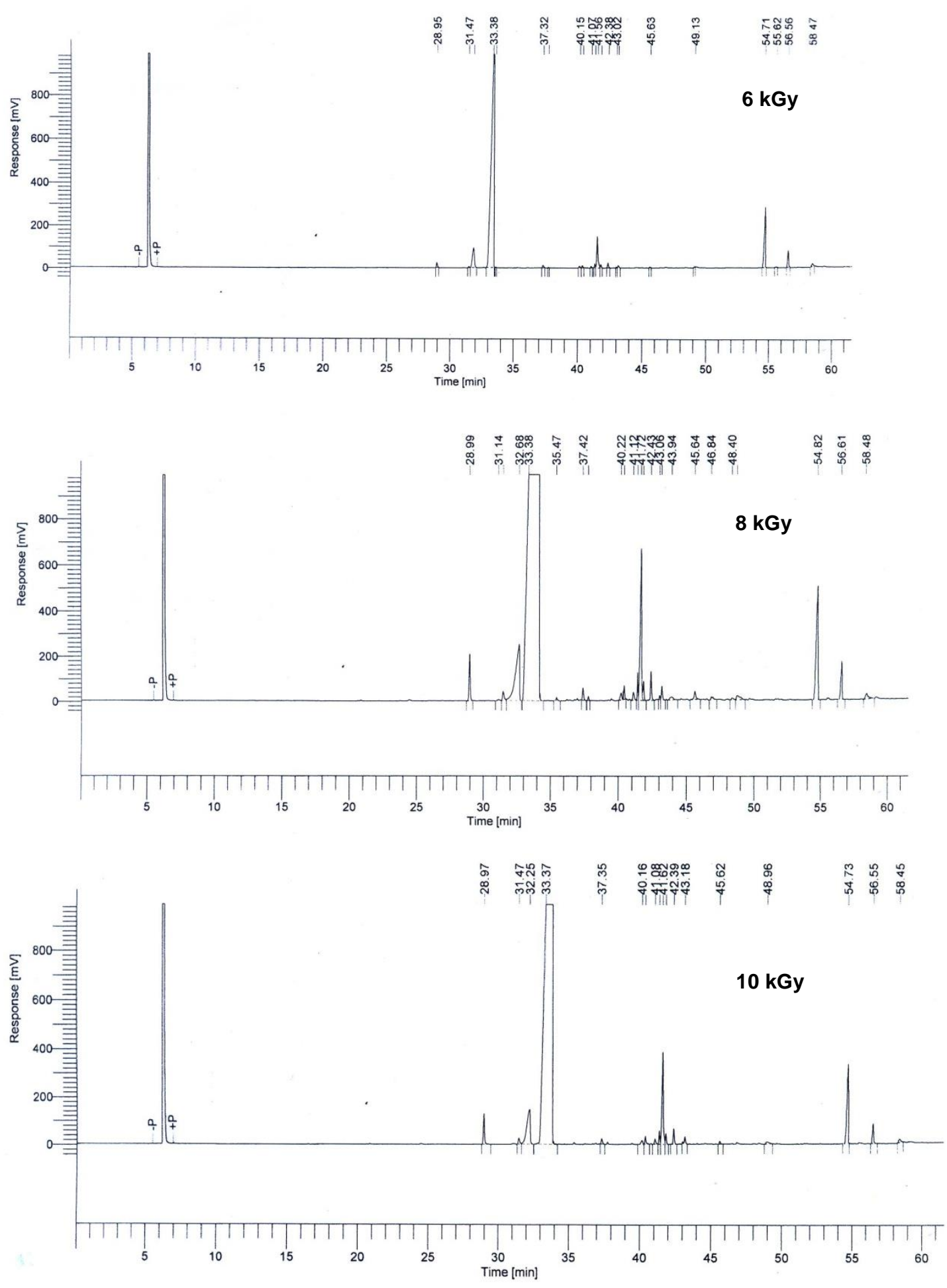

Fig. 2. Gas Chromatograms of anise essential oil treated with different $\gamma$ - irradiation dosed $(6,8$ and 10 KGy) 

Karima Mahmoud; Engy Mohamed and Gamil Ibrahim

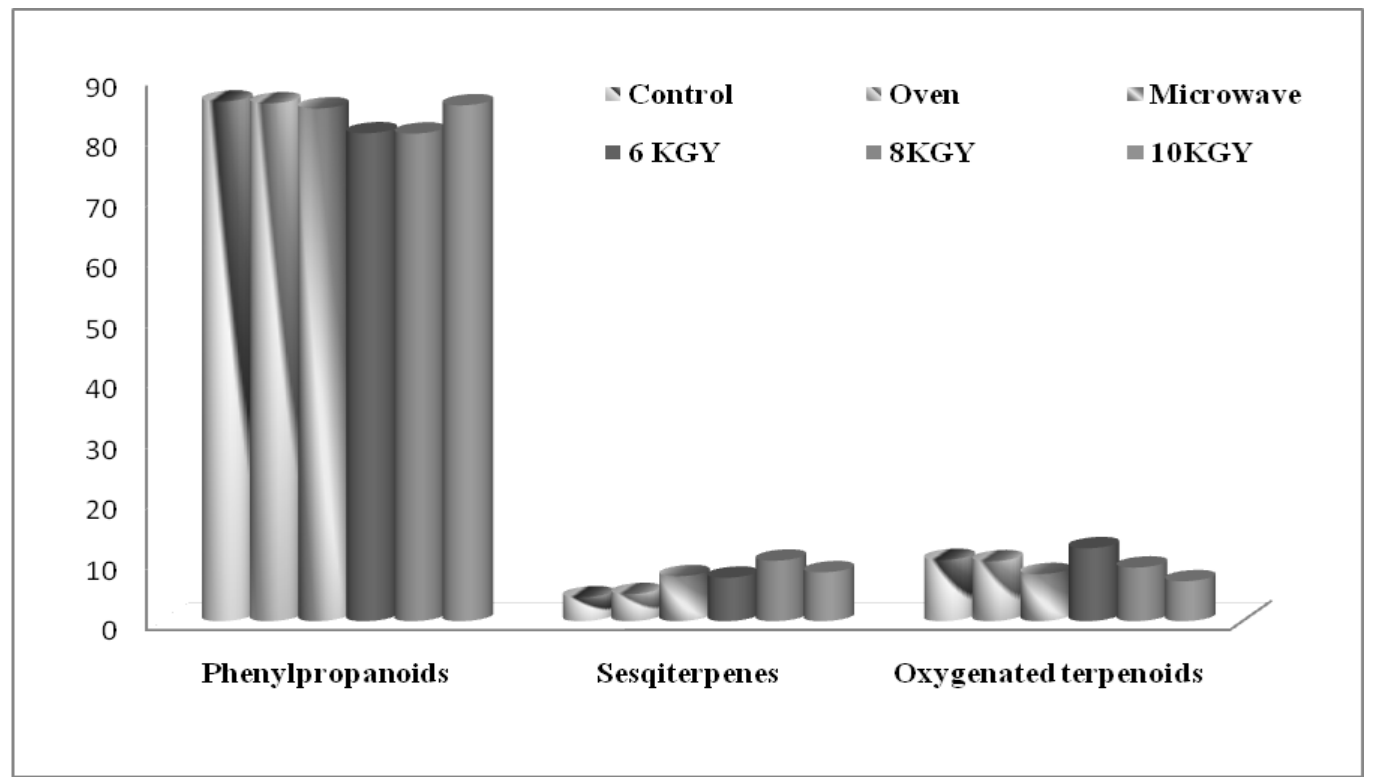

Fig. 3. The total area percentages of the main chemical classes in HD anise oil treated with thermal treatments (electric oven, microwave) as well as $\gamma$-irradiation at three doses

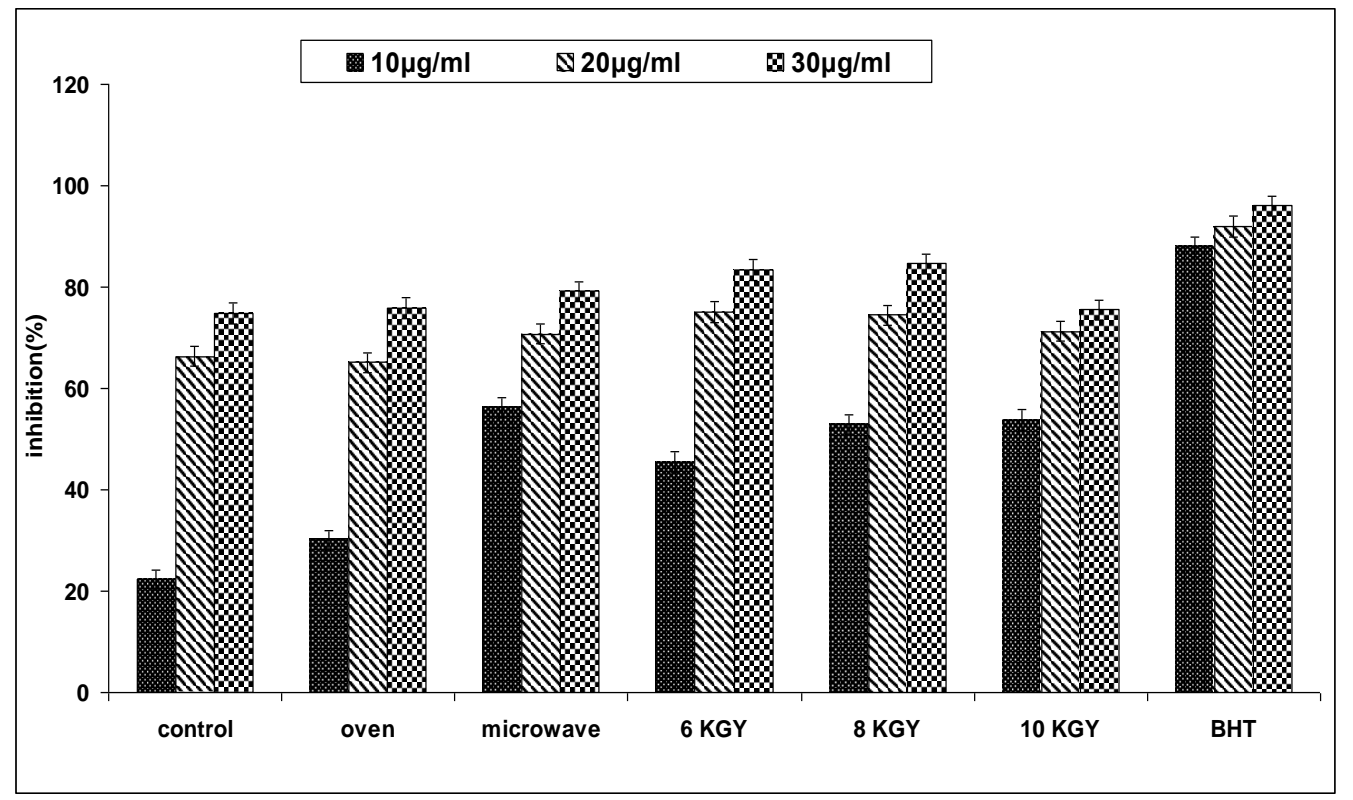

Fig. 4. Scavenging effect of Anise volatile oil on DPPH radicals with different concentrations compared to $\mathrm{BHT} \pm \mathrm{SD}$ 


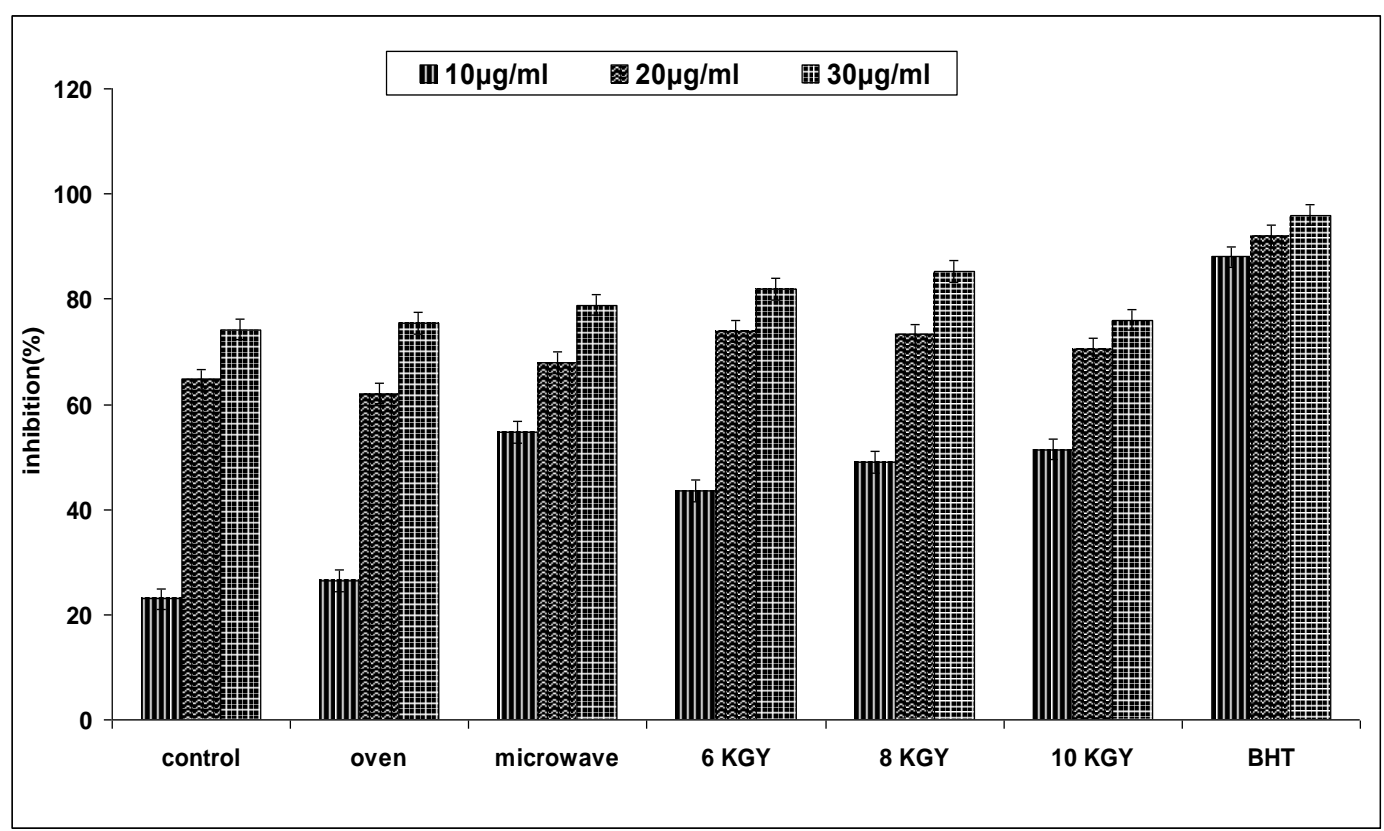

Fig. 5. Scavenging effect of Anise volatile oil on $\beta$-carotene linoleic acid bleaching with different concentrations compared to $\mathrm{BHT} \pm \mathrm{SD}$

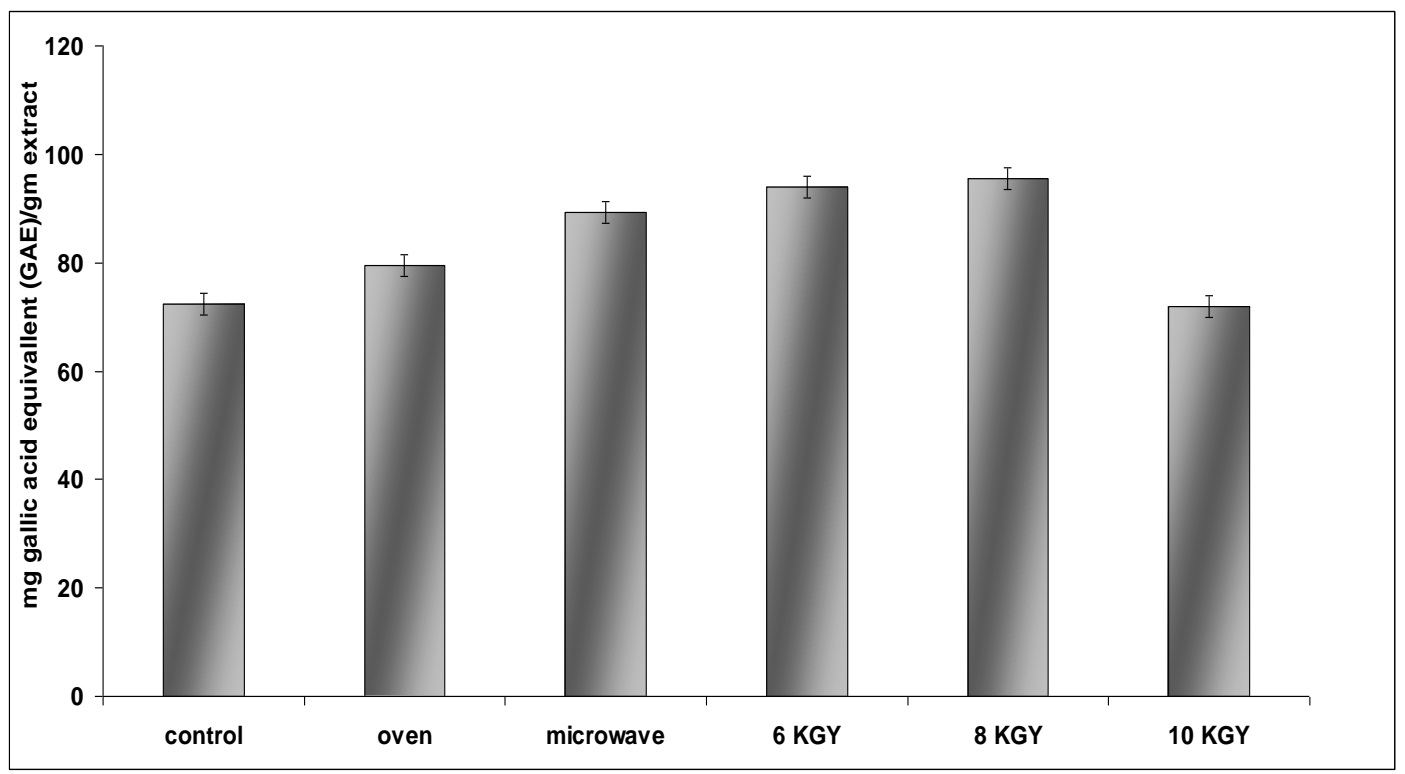

Fig. 6. Total Phenolic content of anise hydrodistilled oil in control, electric oven, microwave and irradiated doses at 6,8, and 10 KGy. 
$\beta$-Carotene bleaching test is commonly used for determination of antioxidant activity of natural compounds because it is carried out in an emulsion, a condition frequently seen in foods. In this model system, the reduction in the orange colour of $\beta$-carotene caused due to the abstraction of a hydrogen atom from one of its methylene groups is assessed. From (Fig. 5), it can be seen that antioxidant activity coefficient (AAC) of the extracts was concentration dependent.

\section{HPLC analysis of $\gamma$-irradiated selected sam- ple}

Identification of phenolic compounds in the selected treatment ( $8 \mathrm{KGy}$ ) -the most effective treatment-essential oil was preliminary performed by HPLC-UV, comparing the relative retention times and UV spectra with those of standard solutions. Concentration of phenolic compounds in the essential oil was comparing HPLC peak areas with those of external standard and the obtained data are reported in Table (2).

Table 2. Effect of $\gamma$-irradiation on phenolic compound of Anise essential oil (treated with 8 KGy).

\begin{tabular}{|lc|}
\hline \multicolumn{1}{|c|}{ Phenolic compound } & Concentration \\
\hline Catechin & $4.72^{*}$ \\
$P$-Qumaric acid & 43.36 \\
Ferulic acid & 21.06 \\
Benzoic acid & 15.73 \\
Cinnamic acid & 6.07 \\
Rurin & 2.53 \\
Quercetin & 0.77 \\
Gallic acid & 2.33 \\
Kampferol & 0.86 \\
\hline
\end{tabular}

*: Values are expressed ad relative area percentage

A total of 9 phenolic compounds (Table 2) were identified in anise essential oil after irradiation with $\gamma$-irradiation at $8 \mathrm{KGy}$ which were gallic acid, catechin, ferulic acid, benzoic acid, Cinnamic acid, rutin, qurectin, $P$-qumaric acid and Kampferol. The obtained results showed that $P$ qumaric acid was the predominant phenolic compound $(43.36 \%)$ followed by ferulic acid which represent $(21.06 \%)$ and benzoic acid (15.73\%). Several studies have determined the effect of $\gamma$ irradiation on total phenolics, but to our knowledge no studies have investigated the effect of $\gamma$ irradiation on individual phenolics in anise essential oil. At irradiation doses of 2.5 to $10 \mathrm{kGy}$, various capsaicinoids in paprika increased or were unaffected with gamma irradiation (Topuz and Ozdemir 2004). Soy flour subjected to $\gamma$-irradiation ranging from 0.5 and $5 \mathrm{kGY}$ resulted in reduced glycosidic conjugates with increased dosage (Variyar et al 2004).

\section{REFERENCES}

Abd El-Mageed M.A. 2007. Effect of microwave of heating and conventional roasting on volatile compounds in oregano leaves, coriander and cumin seeds. J. Agric. Sci. Mansoura University, 32(2): 1521-1535.

Abd El-Mageed, M.A., Farouk, A., El-Massry, K.F., Ramadan, M.M. and Shahin, M.S. 2011. Effect of Microwaves on Volatile Compounds of White and Black Peper (Piper nigrum L.) and their Antioxidant activities. J. Essential OilBearing Plants 14(2): 214 - 223.

Abd El-Mageed, M.A., Mansour, A.F., El-Masry, K.F., Ramadan, M.M., Shabeen, M.S. and Shaaban, H.A. 2012. Effect of microwaves on essential oils of coriander and cumin seeds and their antioxidant and antimicrobial activities. Jeobp, 15 (4):614-627.

Abd El-Mageed, M.A., Shaaban, H.A., Ibrahim, G.E., Mahmoud, K.A. and Osman, F. 2014. Impact of $\gamma$-irradiation on the Aroma Volatiles, Antioxidant and Antimicrobial Activities of Black and White Pepper (Piper nigrum L.). Middle East Journal of Applied Sciences, 4(2): 262276.

Adams, R. 2007. Identification of Essential Oil Components by Gas Chromatography/Mass Spectrometry. Carol Steam, IL: Allured Publishing.

Akgul, N.B., Basaran, P. and Rasco, B.A. 2008. The effect of temperature $\left(-5\right.$ to $\left.130^{\circ} \mathrm{C}\right)$ and fiber direction on the dielectric properties of beef Semitendinosus at radio frequency and microwave frequencies. J. Food Sci. (73): 243-249.

Arslan, N., Gurbuz, B., Sarihan, E.O., Bayrak, A. and Gumuscu, A. 2004. Variation in essential oil content and composition in Turkish anise (Pimpinella Anisum L.) population . Turk. J. Agric. Forest. 28: 173-177.

Avlessi, F., Dangou, J., Wotto, W.D., Alitonou, G.A., Sohounhloue, D.K. and Menut, C. 2004. Antioxidant activities of essential oil from 

and Antiradical activity of Egyptian anise essential oil

Clausena anisata (wild) hook. Comptes Rebdus Chimie, (7): 1057-1061.

Basaran, P. and Akhan, U. 2010. Microwave irradiation of hazelnuts for the control of aflatoxin producing Aspergillus parasiticus. Innov. Food Sci. Emerg. (11): 113-117.

Belitz, H.D. and Grosch, W. 1987. Food Chemistry. Springer, Berlin.

Bendini, A., Gallina-Toschi, T. and Lercker, G. 1998. Influence of $\gamma$-irradiation and microwaves on the linear unsaturated hydrocarbon fraction in spices. Z Lebensm U Forsch A (207): 214218.

Burt, S. 2004. Essential oils: their antibacterial properties and and potent applications food areviw. International Journal of food Microbiology, (94): 223 -253.

Chacko, S., Jayalekshmy, A., Gopalakrishnan, M. and Narayanan, C.S. 1996. Roasting studies on black pepper (Piper nigrum L.) Flavour and Fragrance J. (11): 305-310.

Choi, J., Kim, H.J., Kim, J.H., Chun, B.S., Ahn, D.H., Kim, G. and Lee, J.W. 2010. Changesin colour andantioxidantactivitiesof Hizikia fusiformis cooking dripsbygamma irradiation. LWTFood Sci.Tech.43,1074-1078.

European Pharmacopeia 2005. Council of Europe $.5^{\text {th }}$ ed. strasbourg:EDQM;

Emam, O.A., Farage, S.A. and Aziz, N.H. 1995. Comparative effects of gamma and microwave irradiation on the quality of black pepper. $\mathbf{Z}$. Lebensm. Unters. Forsch., (21): 557-561.

Farkas, J. 1985. Radiation processing of dry food ingredients-a review. Rad Phys Chem (25):271-280.

Fung, D.Y. and Cunningham, F.E. 1980. Effect of microwaves on micro organisms in foods. $\mathbf{J}$. Food Prot; (43): 641-650.

Hashem, M. and Alamri, S. 2010. Contamination of common spices in Saudi Arabia markets with potential mycotoxin-producing fungi. Saudi J. Biol. Sci., 17: 167-175.

lqbal, S., Bhange, M.I. and Anwar, R.F. 2007. antioxidant properties and components of bran extracts from selected wheat varieties commercially available in Pakistan. LWT-Food science \& technology, 40(2): 361-367.

Krzymien, M.E., Carlsson, D.J., Deschênes, L., Mercier, M. 2001. Analysis of volatile transformation products from additives in $\gamma$-irradiated polyethylene packaging. Food Addit Contam (18): 739-749.

Kulisic, T., Radonic, A., Katalinic, V. and Milos, M. 2004. Use of different methods for testing antioxidative activity of oregano essential oil. Food Chem. (85): 633-640.

Leela, N.K. and Vipin, T.M. 2008. Anis seed, p. 331341. In: Parthasarathy, V.A., B. Chempakam, and T.J. Aachariah (eds.). Chemistry of spices. CABI, Wallingford, UK.

Legnani, P.P., Leoni, E., Righi, F. and Zarabini, L.A. 2001. Effect of microwave heating and gamma irradiation on microbiological quality of spices and herbs. Italian J. Food Science, (13): 337-345.

Li, Y.Y. and Yi, Z.Y. 2003. Present situation and development of food antistaling agent and preservatives. J. Beij. Inst. Petrochem. Technol. (11): 18-23.

Mansour, A.F., Abd El-mageed, A.M., Elmassry, K.F., Ramadan, M.M. and Shahin, M.S. 2010. Effect of microwave heating and conventional voosting on the volatile compounds of oregano leaves, (Origanum Vulgare.L) and its antioxidant avtivity. $4^{\text {th }}$ Indernational conference, " Innovation in food science and Nutrition. N.R.C, Cairo, pp. 685-694.

Manzocco, L., Calligaris, S., Mastrocola, D., Nicoli, M.C. and Lerici, C.R. 2001. Review of non-enzymatic browning and antioxidant capacity in processed foods. Trends in Food Science and Technology, (11): 340-346.

Najja, H., Zerria, K., Fattouch, S., Ammar, E., and Neffati, M. 2011. Antioxidant and antimicrobial activities of Allium Roseum. "lazoul", a wild edible endemic spices in north Africa . International journal of food properties, (14): 371-380.

Olson, D.G. 1998. Irradiation of food. Food Technol; 52(1): 56-62.

Podsedek, A., Sosnowska, D., Redzynia, M., and Koziołkiewicz, M. 2008. Effect of domestic cooking on the red cabbage hydrophilic antioxidants. International Journal of Food Science and Technology, 43: 1770-1777.

Radonic, A. and Milos, M. 2003. Chemical composition and in vitro evaluation of antioxidant effect of free volatile compounds from (Saturega Montana L). Free Rodical Research (376): 673-679.

Reverchon, E. and Senatore, F. 1992. Isolation of rosemary oil: Comparison between hydrodistillation and supercritical CO2 extraction. Flavour and Fragrance Journal, 7: 227-230.

Roby, M.H., Mohamed, A.S., Khaled, A., Selim, K. and Ibrahim, K. 2013. Antioxidant and antimicrobial activities of essential oil and extracts of fennel (Foeniculum vulgare L.) and chamo- 
mile (Matricaria chamomilla L.). Industrial Crops and Products (44): 437-445.

Roy, M.K., Takenka, M., Isobe, S. and Tsushida, T. 2007. Antioxidant potential, antiproliferative activities, and phenolic content in water soluble fractions of some commonly consumed vegetables: Effects of thermal treatment. Food Chemistry, 103: 106-114.

Singleton, V.L. 1998. Wine polyphenols. In: Linskens, H.F., Jackson, J.F. (Eds.), Modern Methods of Plant Analysis. New Series, vol. 6. Springer-Verlag, Berlin, pp. 173-219.

Srinivasan, K., 2005. Role of spices beyond food flavouring: Nutraceuticals with multiple health effects. Food Reviews International (21): 167-188.

Stojanov, N. 1973. Anise, Pimpinella anisum, pp. 220-224. In: Stojanov, N. (ed.) Our medicinal plants. Nauka I Izkustvo Press, Sofia, Bulgaria.

Susheela, R.U. 2000. Handbook of spices, seasonings and flavourings pp. 47-48. Lancaster, USA: Technomic Publishing.

Tapsell, L.C., Hemphill, I., Cobiac, L., Patch, C.S., Sullivan, D.R., Fenech, M., Roodenrys,S., Keogh, J.B., Clifton, P.M., Williams, P.G., Fazio, V.A. and Inge, K.E. 2006. Healthbenefits of herbs and spices: the past, the present, the future. The Medical Journal of Australia (185): S4-S24.

Tepe, B., Akpulat, H.A., Sokmen, M., Deferera, D., Yumrutas, O., Aydin, E., Polissiou, M. and Sokmen, A. 2006. Screening of the antioxidant and antimicrobial properties of the essential oils of Pimpinella Anisum and Pimpinella flabellifolia from Turkey. Food Chemistry (79): 719-724.

Thostenson, E.T. and Chou, T.W. 1999. Microwave processing: Fundamentals and applications. Composites: Part A, (30): 10551071.
Topuz, A. and Ozdemir, F. 2004. Influences of gamma irradiation and storage on the capsaicinoids of sun-dried and dehydrated paprika. Food Chem. (86): 509-515.

Tonutti, I. and Liddle, P. 2010. Aromatic plants in alcoholic beverages. A review. Flavour \& Fragrance J. (25): 341-350.

Ullah, H. and Honermeier, B. 2013. Fruit yield, essential oil concentration and composition of three anise cultivars (Pimpinella Anisum L.) in relation to sowing date, sowing rate and locations. Industrial Crops and Products 42: 489499.

Variyar, P.S., Limaye, A. and Sharma, A. 2004. Radiation-induced enhancement of antioxidant contents of soybean (Glycine max Merrill). J. Agric Food Chem (52): 3385-3388.

WHO, 1981. Wholesomeness of irradiated food. Report a joint FAO/IAEA/WHO expert Committee. Technical Report Series 659. World Health Organization, Geneva: 7-34.

WHO, 1999. High-dose irradiation: Wholesomeness of food irradiated with doses above 10 kGy. Report of a joint FAO/IAEAWHO study group. WHO Technical Report Series 890. World Health Organization, Geneva.

Yan, F., Beyer, E.M., Azizi, A. and Honermeier, B.L. 2011. Effect of sowing time and sowing density on fruit yield, essential oil concentration and composition of anise (Pimpinella Anisum L.) under field conditions in germany. J. Med. Spice Plants (16): 26-33.

Zheljazkov, V.D. 2013. Essential oil composition and yield of anise from different distillation times. Hort Science, 48(11): 1393-1396. 